\title{
Setting the table, not running it: An inclusive approach to access to healthy foods
}

\author{
Karen S. Emmerman a ${ }^{*}$ \\ University of Washington \\ in collaboration with \\ lauren Ornelas b \\ Food Empowerment Project
}

Submitted January 22, 2021 / Published online September 16, 2021

Citation: Emmerman, K. S. (Author) \& Ornelas, l. (Contributor). (2021). Setting the table, not

running it: An inclusive approach to access to healthy foods. Journal of Agriculture, Food Systems,

and Community Development, 10(4), 47-50. https://doi.org/10.5304/jafscd.2021.104.026

Copyright (C) 2021 by the Author. Published by the Lyson Center for Civic Agriculture and Food Systems. Open access under CC-BY license.

\section{Introduction}

Food Empowerment Project (F.E.P.) is a vegan food justice nonprofit in northern California. We focus on making a more just and sustainable food system for everyone involved. Since injustice in the food system crosses the species barrier, we work to connect the dots between the exploitation of human and nonhuman animals. We focus our efforts on four main areas: ending the use of animals in the food system, improving access to healthy foods in Black, Brown, and low-income communities, exposing the worst forms of child labor (including slavery) in the chocolate industry, and advocating for farmworker rights. These seemingly disparate areas have much in common: they are interlocking forms of oppression, marginalization, and domination in the food system. We recognize that the intersecting nature of oppression necessitates a nuanced response. For example, as an organization working on both farm-

a* Corresponding author: Karen S. Emmerman, PhD., Part-Time Lecturer, Department of Philosophy, University of Washington; Savery Hall, Room 361, Box 353350; Seattle, WA 98195 USA; emmerman@,uw.edu

in collaboration with

b lauren Ornelas, Founder and President, Food Empowerment Project; info@,foodispower.org

\section{Author Note}

The author (Karen S. Emmerman) is a member of Food Empowerment Project's advisory board and a donor to the organization. She did not receive compensation for writing this piece nor will she benefit financially in any way from having written it. 
worker justice and food apartheid, we cannot advocate for lowering the price of food as this would negatively impact produce workers who already suffer grave systemic injustice. Instead, we advocate for equality of access and living wages for everyone. ${ }^{1}$ In this piece, we focus on our approach to the lack of access to healthy foods, and specifically our community-based efforts in Vallejo, California.

\section{By Invitation Only}

It is well-documented, including in the pages of this journal, that people living in Black, Brown, Indigenous, and low-income communities lack access to the healthy foods necessary for living a flourishing life. Though we passionately believe that access to fresh fruits and vegetables as well as other healthy foods is a basic human right, F.E.P. takes a "by invitation only" approach to working with communities on access issues. In other words, we only enter communities where we have been invited by residents and community leaders. We believe communities know what they want and need as well as whose expertise and approach will be most valuable to achieving their goals. Well-intentioned nongovernmental organizations (NGOs) and government agencies sometimes approach access issues by telling communities what they need and how to get it. F.E.P.'s approach hinges on respect-for the epistemic authority of community members, for the voices of activism and resistance already present in the communities, and for the ability of the communities themselves to know what solutions would best serve their interests. As a result, we go only where we are invited.

\section{Vallejo, California-Bringing Community Voices to the Table}

In 2012, F.E.P.'s founder and then executive director, lauren Ornelas, met with David Hilliard, a founding member of the Black Panther Party and the Huey P. Newton Foundation, to discuss the Black Panther Party's free breakfast program. When lauren showed him our reports and explained the work we had done on access issues in San José, Hilliard asked if we could undertake similar work in the community of Vallejo. The city is home to a diverse population of approximately 120,000. One-third of residents are white, and the remaining two-thirds are made up of Asian (predominantly Filipinx), Latinx, Black, and other ethnicities. Though thrilled about Hilliard's interest, our first step was to gauge the interest of the broader Vallejo community in partnering with us on their access issues. We reached out to community organizations like the Vallejo People's Garden and Global Center for Success to see if our approach and expertise met their needs. Once we were certain that F.E.P. would be a welcomed partner in the work of understanding and ameliorating the injustices faced by Vallejo residents, we got to work.

Assessing what foods are available and where is a crucial step to understanding the access issues communities face. Our assessment method involves surveying local grocery stores, convenience stores, and liquor stores (anywhere that sells food) to understand exactly which foods are available and where. We already had such a survey tool from our previous work on access issues in San José, but the ethnic make-up of Vallejo, importantly, is different from San José, which necessitated changes to the survey tool. Working with our Vallejo community partners, we gathered feedback from the Black and Filipinx residents of Vallejo about culturally relevant foods so that we could add those to the Latinx foods already represented in the tool. This part of our process is fundamental to showing respect for communities. Variations in ethnicity mean variations in what foods people want, need, and know how to cook. A survey that looks only for a particular type of food will fail to accurately reflect the access issues faced by specific groups of the local population.

\footnotetext{
${ }^{1}$ Food Empowerment Project does not use the common term "food deserts" to describe areas impacted by lack of access to healthy foods. We prefer "food apartheid." Deserts are naturally occurring phenomena. "Food apartheid" better captures the deliberate systemic, political, and racist origins of the food crisis faced in Black, Brown, Indigenous, and low-income communities.
} 
After making the necessary changes to the survey tool, we began our survey. Volunteers from Touro University, Vallejo People's Garden, the Global Center for Success, and F.E.P. went to every foodselling establishment in Vallejo, clipboard in hand. We published the results of this survey in our report, Vallejo: City of Opportunity Lacks Access to Healthy Food. Although the survey results tell a dark story about the proliferation of liquor and convenience stores and the history of large chain grocery stores abandoning Vallejo for more suburban locales and clienteles (leaving restrictive deeds in their wake that prevent new grocery stores from moving in), we knew that understanding the full picture of how lack of access to healthy foods affects Vallejo residents meant talking with the residents themselves. This gave rise to our community focus groups.

In May 2017, F.E.P. conducted six focus groups with Vallejo residents, including those experiencing homelessness. Our goal was to uncover the experiences of residents buying and receiving food in Vallejo. Narrative is critically important to work on food access issues. Hearing people's stories and understanding the systemic barriers that undermine their ability to care for themselves and their families is essential to thinking about solutions and how to advocate for them at the corporate, legislative, and regulatory levels. Recognizing that community members are experts with knowledge that we need to do our work, we compensated our focus group members with US\$50 and served them a vegan meal. The results of these community conversations were published in our report, Bringing Community Voices to the Table: Food Access in Vallejo, CA, Focus Groups Qualitative Data Analysis Results.

As we had done with our San José reports, we distributed our Vallejo reports to policy-makers at the local, state, and federal levels. The collaborative nature of our work is underscored by the fact that we were able to give the reports to Vallejo People's Garden to be used in their fundraising efforts. The reports helped make the compelling case that food sovereignty in the form of a community garden is a key part of solving access issues in Vallejo. To help underscore the importance of the programs they were working on, the Solano County Health Department distributed so many copies of the report in the community that they depleted our reserves and paid our reprinting costs. Our grassroots work in the community that started with lauren and David Hilliard's meeting blossomed into a collaborative effort, one that resulted in a better understanding of the issues Vallejo residents face and two reports that served advocacy efforts in the community.

\section{From Table to Tent}

Our efforts in communities are focused on providing a table where everyone can sit and share their expertise, experiences, and visions for the future. Inviting all stakeholders to the table is essential to access work because communities know best what they are experiencing and what will be needed to effectively right the injustices they face. Our hope, however, is that what starts as a table will quickly transform to a tent-one where even more organizations, residents, policy-makers, and advocates come together collaboratively to undertake the complex work of restoring access to healthy foods for communities.

In Vallejo, this tent has materialized in a variety of ways. In 2020 F.E.P. sponsored our fifth annual Vallejo Healthy Food Fest (held online in 2020 due to COVID-19). These events put an emphasis on local resources, pulling from the culinary, aesthetic, and activist agents of change living in Vallejo. Always coordinated by a Vallejo resident or former resident, our Vallejo Healthy Food Fests include vegan cooking demonstrations by Black, Filipinx, and Latinx chefs cooking culturally appropriate foods, performances by local dance groups, and information from local groups working on food-related issues and advocacy. These are occasions to celebrate the strength found in Vallejo's diversity and to build stronger partnerships to fight the food system injustices that affect Vallejo so deeply.

The tent also includes working together with a coalition of individuals to form a worker-owned 
cooperative in Vallejo so that residents can have access to a full-service grocery store. Worker-owned cooperatives provide many benefits, including an opportunity for workers to control their own working conditions and compensation.

We believe that communities have the power to use their talents and strengths to create change that will improve residents' ability to live flourishing, healthy lives. Arguably, changes stemming from community efforts are the most important to generating long-term improvements to food access. We also know that with our reports distributed to policy-makers, we have expanded the tent to include those in the position to generate long-term, systemic changes at the level of legislation and regulation. More and more local, state, and federal legislators are becoming aware of access issues for Black, Brown, Indigenous, and low-income communities. We are hopeful that our work, centered on respect for community members' knowledge, expertise, and advocacy, can help light the way forward to meaningful change that benefits communities hardest hit by systemic racism and injustice.

\section{Resources}

\section{Media:}

Peters, A. (2017, November 27). How closing grocery stores perpetuate food deserts long after they're gone. Fast Company. https://www.fastcompany.com/40499246/how-closing-grocery-storesperpetuate-food-deserts-long-after-theyre-gone

Velasco, P. (2018, January 5). The unexpected challenges of living in a food desert. Marketplace. Retrieved from https://www.marketplace.org/2018/01/05/world/unexpected-challenges-living-food-desert/

F.E.P. Access Reports (all are available at https:// foodispower.org/fep-printed-materials/):

- Vallejo: City of Opportunity Lacks Access to Healtby Food

- Bringing Community Voices to the Table: Food Access in Vallejo, CA, Focus Groups Qualitative Data Analysis Results

- Bringing Community Voices to the Table: Food Empowerment Project: Food Access Issues in San José Focus Groups Qualitative Data Analysis Results

- Shining a Light on the V alley of Heart's Delight: Taking a Look at Access to Healthy Foods in Santa Clara County's Communities of Color and Low-Income Communities

\section{Food Empowerment Project}

- About F.E.P.: https://foodispower.org/

- Access and health: https://foodispower.org/access-health/

- Human labor and slavery: https:// foodispower.org/human-labor-slavery/

- Land animals in the food system: https://foodispower.org/animals-on-land/

- Marine animals in the food system: https://foodispower.org/animals-of-the-sea-2/ 